\title{
School factors causing Vietnamese adolescents' anxiety in secondary schools
}

\section{Hong-Van Thi Dinh ${ }^{1}$, Le-Hang Thi Do ${ }^{2 *}$, Mai-Huong Thi Phan ${ }^{3}$}

1. PhD, Vice-Dean, Department of Psychology and Education, University of Education, Hue University, No 32, Le Loi st, Hue city, Vietnam; Email: dthvan@hueuni.edu.vn or dinhthihongvan@dhsphue.edu.vn; ORCID: https://orcid.org/0000-0002-1665-9083

2. PhD, Senior Researcher, Insitute of Psychology, Viet Nam Academy of Social Sciences, No 37, Kim Ma Thuong St, Hanoi city, Vietnam; Email of the corresponding author: dothilehang@gmail.com or dolehang2020@gmail.com; ORCID: https://orcid.org/0000-0002-0038-9306

3. PhD, Associate Professor, Advanced Researcher, Insitute of Psychology, Viet Nam Academy of Social Sciences, No 37, Kim Ma Thuong St, Hanoi city, Vietnam. E-mail: huongphanmai@gmail.com; ORCID: https://orcid.org/0000-0001-5759-2906

\begin{abstract}
Anxiety is regarded as an emotion characterized by feelings of tension, worried thoughts, and physical changes like increased blood pressure, and it is a common phenomenon for people in general and adolescents in particular. The study aimed to determine the factors that cause anxiety among adolescents in Vietnam under the influence of gender and grade. A group of 749 Vietnamese secondary school students participated in the survey. Results showed that scores and exams caused the most anxiety for participants. Factors related to scores and exams created more anxiety for females than males. Factors related to communicating with friends, teachers, school/classroom facilities, and school safety caused more anxiety for students in grades 6,7 , and 8 than those in grade 9. Our study suggests that prevention and intervention programs should be promoted to minimize anxiety for adolescents from the pressure of scores, exams, and the impact of gender and grade.
\end{abstract}

Keywords: adolescents, anxiety, grade, secondary school, scores, gender

Article Received: 23 October 2020, Revised: 03 November 2020, Accepted: 24 December 2020

\section{INTRODUCTION}

Adolescence is a crucial developmental stage in the life of every human being. This transition period from childhood to adult is marked with significant physiological and psychological changes (Grant, 2013). The development of the ego, the need for equal rights in adult relationships, and the expansion of social relations have made adolescents live in a mental world filled with emotions. It can be said that this is the stage with the most emotional and behavioral disorders (Silk et al., 2003). Emotions such as anger, boredom, and anxiety that persist in mild or severe forms can start at this age (Langelier, 2011). Anxiety is of of the most common phenomenon in teenagers' age (Dinh, 2014).

Anxiety is the painful feeling that we typically recognize as uneasiness, apprehension, or worry (Seligman et al., 2001). Spielberger et al. (1970) 
clarified two different statuses of anxiety: state anxiety and trait anxiety. State anxiety (A-State) reflects a "transitory emotional state or condition of the human organism that is characterized by subjective, consciously perceived feelings of tension and apprehension, and heightened autonomic nervous system activity" (Spielberger et al., 1970, p. 3). In contrast, trait anxiety denotes "relatively stable individual differences in anxiety proneness and refers to a general tendency to respond with anxiety to perceived threats in the environment" (Spielberger et al., 1970, p. 3).

Uncontrolled anxiety can result in anxiety disorders. In children and adolescents, anxiety is considered one of the most common psychological disorders (Costello et al., 2003). The rate of anxiety disorder among adolescents in the population ranged from 9 to $21 \%$ (Mardomingo, 2005). The prevalence of anxiety disorders among children and adolescents with chronic illness was about 20-50\% (Cobham et al., 2019). Liu et al. (2018) conducted a study on 50,361 children and adolescents in rural areas of China from 2008 to 2015. Findings from this study revealed that seven percent of students were at risk for overall anxiety. However, over half of the students were at risk for at least one subcategory of anxiety. Students at higher risk for anxiety included students from poorer counties and families, female students, secondary school students, and students with lower academic performance levels. Another study from Deb et al. (2000) on 460 adolescents (220 boys and 240 girls), aged 13-17 years in India showed that anxiety was prevalent in the sample with $20.1 \%$ of boys and $17.9 \%$ of girls suffering from high anxiety.

A cross-cultural study was conducted by Essau et al. (2008) to compare the level of anxiety among adolescents in German and Hong Kong. A total of 1,022 adolescents (594 from Germany and 428 from Hong Kong) between the ages of 12 and 17 were investigated. Results showed that adolescents in Hong Kong reported significantly higher levels of anxiety symptoms than adolescents in Germany. Anxiety symptoms showed differences across cultures. Individually, academic motivational goals to compete to get good grades and be rewarded for their performance correlated significantly with anxiety symptoms in Hong Kong. In Germany, anxiety symptoms were markedly correlated with reinforcement received for anxiety-related problems (i.e., instrumental learning) and parental verbal transmission about the danger of anxiety (i.e., informational knowledge). The findings underscored the importance of cultural factors on adolescent's anxiety.

In Vietnam, the proportion of adolescents with anxiety disorders was reported relatively high. A study by Nguyen et al. (2013) on 1161 secondary students in Can Tho City, Vietnam, showed an anxiety disorder rate of $22.8 \%$. Nguyen's (2018) study on 923 adolescents in Ho Chi Minh City showed that $12 \%$ of participants had anxiety disorders.

Evidence has shown that some groups of adolescents were at higher risk of having anxiety than other groups. For example, regarding gender, females were more anxious than males (Mendle et al., 2019; Shen et al., 2015). However, some other studies showed that males were at a higher level of anxiety than females (Deb et al., 2010). Xing (2008) found that older students and female students had higher rates of anxiety than younger and male students. Children in rural areas were more anxious than those in urban areas (Jin et al., 2014). Deb et al. (2010) revealed that adolescents belonging to the middle socio-economic group suffered more anxiety than those from high or low socioeconomic groups. Adolescents with working mothers were found to be more anxious.

Some research results also showed that there were plenty of risk factors that led to anxiety among adolescents, such as physical or 
emotional abuse by the family, high educational stress (Mendle et al., 2019; Nguyen et al., 2013). Grant (2013) generalized the etiological factors that led to anxiety among adolescents: "(1) Biological Factors (changes in adolescence such as increased hormone levels via the hypothalamus and the pituitary gland and the physical changes), (2) Interpersonal Stress (problems in relationships with parents and friends), (3) Cognitive Factors (Cognitive vulnerabilities, anxiety sensitivity)" (p. 45).

Some studies also revealed the relationship between high anxiety and low academic performance (Liu et al., 2018; Yousefi et al., 2010; Owens et al., 2008) and low self-esteem (Nguyen et al., 2019). Pine et al. (1999) said that anxiety could interfere negatively with social life, general well-being, development of social skills, and academic performance (Pine et al., 1999). To develop intervention programs to reduce the risk of anxiety, it is essential to understand school factors that are believed to be the core environment that an adolescent interacts in everyday life, affecting anxiety among adolescents.

This study, therefore, aimed to answer the following two questions:

1. What school factors create anxiety feeling for adolescents at secondary schools in the two biggest cities in Vietnam?

Table 1. Characteristics of participants
2. How gender and grade-related factors create anxiety among those adolescents?

\section{METHODS}

\section{Study design}

A cross-sectional study design was applied. All data were collected from March to April 2019.

\section{Sampling and Participants}

The sample was purposively selected from four secondary schools in Ha Noi capital city và Ho Chi Minh city, Vietnam, of which two schools are from each city. These two cities represent the Northern and Southern areas as the two biggest cities in Vietnam. Four selected secondary schools were public ones that were neither special nor schools in deprived areas. We randomly selected one class of each grade from grade six to grade nine, making up a total of 16 classes for the study. The convenience sampling method was used to recruit students who volunteered to help with the research and to administer the survey. The survey instrument was distributed to 780 Vietnamese students. Among these, 749 participants (response rate of $96.1 \%$ ) completed and returned the questionnaire. All these data were included in the analysis. Table 1 shows the general characteristics of the study sample.

\begin{tabular}{|c|c|c|}
\hline \multicolumn{2}{|l|}{ Variables } & Value $-\mathbf{N}^{*}[\%]$ \\
\hline \multicolumn{3}{|c|}{ Individual characteristics } \\
\hline \multirow{2}{*}{ Gender } & Male & $392[52.3 \%]$ \\
\hline & Female & $357[47.7 \%]$ \\
\hline \multirow{4}{*}{ Grade } & Grade 6 & $189[25.2 \%]$ \\
\hline & Grade 7 & $192[25.6 \%]$ \\
\hline & Grade 8 & 207 [27.6\%] \\
\hline & Grade 9 & $161[21.5 \%]$ \\
\hline
\end{tabular}




\begin{tabular}{|l|l|l|}
\hline \multicolumn{2}{|l|}{ Environmental characteristics } & \\
\hline \multirow{2}{*}{ Living area } & Hanoi & $363[49.3 \%]$ \\
\cline { 2 - 3 } & Ho Chi Minh city & $386[51.7 \%]$ \\
\hline Total & $\mathbf{7 4 9}[\mathbf{1 0 0 \%}]$ \\
\hline
\end{tabular}

\section{Tool for data collection}

The self-completed questionnaire was used to collect data that included questions about the school's factors impact students' anxiety. These questions were developed from the results of a qualitative study among 90 students in Hanoi. Participants in this were asked to answer the question: "What factors at school make you feel anxious?". Data-driven codes were developed after repeated analysis of the raw information. Using conventional coding, we collected six school factors from 186 answers that led to anxiety among students. The six factors were:

1. Scores and exams: are factors related to achievement evaluation, test pressure (taking tests, oral examination, low test scores, failing tests, worrying about failing from excellent students, worrying about not achieving high scores...)

2. Relationship with friends in class: relating to the connection with classmates such as being misunderstood, being badly talked, being ostracized.

3. Communication with teachers: the connection between students and teachers related to exchanging exercises, asking for help.

4. School/class facilities relate to cleanliness, crowded canteen, low and slow services quality, dirty and smelly toilet.

5. School safety: relating the safe feeling of students at school such as bullying, being attacked with weapons.

6. Factors related to studying: including students' attitude in obeying school rules, the connection between teachers and parents, being punished by teachers, not doing homework, being late for school, etc.
Based on the results of the qualitative study, we developed an official survey questionnaire, which listed six above factors. Each factor has two options, in which " 1 " indicates the factor was the cause of anxiety while " 0 " did not. Other demographic information was included, such as gender and grade.

\section{Data analysis}

We used SPSS 22.0 to analyze descriptive and inference statistics (Corp, 2012). Descriptive statistics with prevalence to describe school factors that caused anxiety among adolescents. Then, binary logistic regression modeling was carried out, in which six dependent variables were included. Factors related to scores and exams, relationship with friends in class, communication with teachers, school/class facilities, school safety, factors related to subjects were binary variables, and independent variables were gender (Boy - Girl) and grade (67-8-9). $95 \%$ confidence interval (CI) for statistics of interest were calculated. A significance level of .05 was used.

\section{RESULTS}

\section{Factors causing anxiety among adolescents}

Table 2 illustrate factors of anxiety among adolescents. Findings showed that $91.1 \%$ of adolescents reported that their anxiety related to scores and exams at school, while only $57.9 \%$ reported the cause of subjects studying at school. $47.9 \%$ of participants mentioned school safety as a reason for their anxiety. The factor that was 
least mentioned was school/class facilities, with

Table 2. Factors of anxiety among adolescents

\begin{tabular}{|l|c|l|}
\hline \multicolumn{1}{|c|}{ School factors } & N & Percentage \\
\hline Scores and exams & 656 & 91.1 \\
\hline $\begin{array}{l}\text { Relationship with } \\
\text { friends in class }\end{array}$ & 292 & 40.6 \\
\hline $\begin{array}{l}\text { Communication } \\
\text { with teachers }\end{array}$ & 309 & 42.9 \\
\hline
\end{tabular}

Table 3 reported outcomes from binary logistic regression models of gender and grade for six school-based factors caused anxiety for students. For each school factor, there were three models, in which models $A\left(A_{1}\right.$ to $\left.A_{6}\right)$ and $B\left(B_{1}\right.$ to $\left.B_{6}\right)$ described statistics of prediction of separate gender and grade tương ứng; models $\mathrm{C}\left(\mathrm{C}_{1}\right.$ to $\mathrm{C}_{6}$ ) included both variables as independent variables. Odds ratios (ORs) and 95\% confidence interval $(95 \% \mathrm{CI})$ for ORs were reported in this table.

The model results showed that gender and grade associated with school factors cause anxiety for students according to the following trends.

\section{Prediction of Gender}

Results in $A$ models $\left(A_{1}\right.$ to $A_{6}$ ), where gender was as a single predictor for dependent variables, revealed that gender was statistically significantly associated with anxiety caused by scores and examinations $(\mathrm{OR}=.565, \mathrm{p}=.022$, 95\% CI [.347-.920]) but was not statistically significantly correlated with the remaining five other factors $(p>.2)$. The result inferred that males were more anxious about exams and scores than females. However, both sexes were at the same risk of having anxiety in relationship with classmates, communication with teachers, school/class facilities, school safety, and factors related to studying.

\section{Prediction of Grade}

one-third of the students.

\begin{tabular}{|l|l|l|}
\hline $\begin{array}{l}\text { School/Class } \\
\text { facilities }\end{array}$ & 251 & 34.9 \\
\hline School safety & 345 & 47.9 \\
\hline $\begin{array}{l}\text { Factors related to } \\
\text { subjects }\end{array}$ & 417 & 57.9 \\
\hline
\end{tabular}

\section{Prediction of gender and grade for factors causing anxiety among adolescents}

The $\mathrm{B}$ models $\left(\mathrm{B}_{1}\right.$ to $\mathrm{B}_{6}$ ), which examined the association of grade and anxiety, showed that students from grades 6 to 8 might have twice to three times more anxious in relationship with classmates than those in grade $9\left(\mathrm{OR}_{\text {grade }}=2.28\right.$, $\mathrm{p}=.001,95 \%$ CI $[1.430-3.655], \mathrm{OR}_{\text {grade }}=3.12$, $\mathrm{p}=.000,95 \%$ CI [1.969-4.961], $\mathrm{OR}_{\text {grade } 8}=2.20$, $\mathrm{p}=.001,95 \%$ CI 1.390-3.489]); Communication with teachers $\left(\mathrm{OR}_{\text {grade }}=2.39, \mathrm{p}=.000,95 \% \mathrm{CI}\right.$ [1.526-3.766], OR $\mathrm{OR}_{\text {grade } 7}=2.45, \mathrm{p}=.000,95 \% \mathrm{CI}$ [1.571-3.837], OR $\mathrm{OR}_{\text {grade } 8}=1.73, \mathrm{p}=.016,95 \% \mathrm{CI}$ [1.109-2.701]); School/class facilities $\left(\mathrm{OR}_{\text {grade6}}=3.13, \mathrm{p}=.000,95 \%\right.$ CI [1.937-5.083], $\mathrm{OR}_{\text {grade }}=2.19, \mathrm{p}=.001,95 \%$ CI [1.351-3.554], OR $_{\text {grade } 8}=1.83, \mathrm{p}=.014,95 \%$ CI [1.134-2.981]); School safety $\left(\mathrm{OR}_{\text {grade }}=2.69, \mathrm{p}=.000,95 \% \mathrm{CI}\right.$

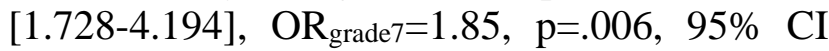
[1.199-2.871], OR grade $8=1.92, \mathrm{p}=.003,95 \%$ CI [1.248-2.957]).

\section{Prediction of both gender and grade}

Adding the gender factor to the model, the $\mathrm{C}$ models (C1 to C6) showed that excepting factors related to studying, all other factors were significantly related to students' anxiety. However, in five models from $\mathrm{C} 1$ to $\mathrm{C} 5$, only one dependent factor was a predictor of independent factor. Model $\mathrm{C} 1$ revealed that gender was a predictor factor for anxiety $(\mathrm{OR}=.551, \mathrm{p}=.018,95 \%$ CI [.336-.903]. This seemed to be consistent across all grades. 
After controlling sex, finding indicated that grade statistically significantly predicted anxiety in scores and exams, relationship with friends in class, communication with teachers, school/class facilities, school safety, factors related to studying. Specifically, the Odds of having anxiety caused by those factors for students in grades $6,7,8$ were about 2-3 times higher than that of grade 9 .

The predictive role of gender and grade was controlled by other factors in multiple binary regression models ( $\mathrm{C}$ models) that were consistent with its role in the models with the single independent variable (A and B models). 
Table 3. Models of prediction for school factors causing anxiety among students (Binary logistic regression)

\begin{tabular}{|c|c|c|c|c|c|c|c|c|c|c|}
\hline \multirow{3}{*}{\multicolumn{2}{|c|}{$\begin{array}{l}\text { Independent } \\
\text { variable }\end{array}$}} & \multicolumn{9}{|c|}{$\begin{array}{l}\text { Dependent variables: School factors causing anxiety } \\
\text { OR [CI 95\%] }\end{array}$} \\
\hline & & \multicolumn{3}{|c|}{ Scores and exams } & \multicolumn{3}{|c|}{ Relationship with friends in class } & \multicolumn{3}{|c|}{ Communication with teachers } \\
\hline & & Model A1 & Model B1 & Model $\mathrm{C}_{1}$ & Model A2 & Model B 2 & Model $\mathrm{C}_{2}$ & Model A3 & Model B3 & Model C3 \\
\hline \multirow[t]{2}{*}{ Sex } & Male & $\begin{array}{l}.565^{*} \quad[.347- \\
.920]\end{array}$ & & $\begin{array}{l}.551 *[.336- \\
.903]\end{array}$ & $\begin{array}{l}.831 \quad[.617- \\
1.118]\end{array}$ & & $\begin{array}{l}.875[.645- \\
1.187]\end{array}$ & $\begin{array}{l}1.144[.852- \\
1.536]\end{array}$ & & $\begin{array}{l}1.226 \\
{[.906-} \\
1.659]\end{array}$ \\
\hline & Female & 1 & & 1 & 1 & & 1 & 1 & & 1 \\
\hline \multirow[t]{4}{*}{ Grade } & 6 & & $\begin{array}{l}.742 \\
{[.385-1.43]}\end{array}$ & $\begin{array}{l}.715 \\
{[.369-} \\
1.384]\end{array}$ & & $\begin{array}{l}2.286 * * * \\
{[1.430-} \\
3.655]\end{array}$ & $\begin{array}{l}2.355 * * * \\
{[1.468-} \\
3.779]\end{array}$ & & $\begin{array}{l}2.397 * * * \\
{[1.526-} \\
3.766]\end{array}$ & $\begin{array}{l}2.512 * * * \\
{[1.593-} \\
3.962]\end{array}$ \\
\hline & 7 & & $\begin{array}{l}1.016 \\
{[.513-2.01]}\end{array}$ & $\begin{array}{l}.940 \\
{[.472-} \\
1.872]\end{array}$ & & $\begin{array}{l}3.125 * * * \\
{[1.969-} \\
4.961]\end{array}$ & $\begin{array}{l}3.162 * * * \\
{[1.982-} \\
5.045]\end{array}$ & & $\begin{array}{l}2.455 * * * \\
{[1.571-} \\
3.837]\end{array}$ & $\begin{array}{l}2.579 * * * \\
{[1.640-} \\
4.054]\end{array}$ \\
\hline & 8 & & $\begin{array}{l}1.382 \\
{[.675-2.83]}\end{array}$ & $\begin{array}{l}1.511 \\
{[.728-} \\
3.138]\end{array}$ & & $\begin{array}{l}2.203 * * * \\
{[1.390-} \\
3.489]\end{array}$ & $\begin{array}{l}2.268 * * * \\
{[1.426-} \\
3.609]\end{array}$ & & $\begin{array}{l}1.731 * \\
{[1.109-} \\
2.701]\end{array}$ & $\begin{array}{l}1.752 * * \\
{[1.119-} \\
2.743]\end{array}$ \\
\hline & 9 & & 1 & 1 & & 1 & 1 & & 1 & 1 \\
\hline \multicolumn{2}{|c|}{ Constant } & $2.45 * * *$ & $2.13 * * *$ & $2.48 * * *$ & $-.321 * *$ & $-1.150 * * *$ & -1.105 & $-3.91 * * *$ & $-.930 * * *$ & $-1.067 * * *$ \\
\hline \multicolumn{2}{|c|}{$\mathrm{p}$} & .020 & .323 & .042 & .221 & .000 & .000 & .371 & .000 & .000 \\
\hline \multicolumn{2}{|c|}{ Nagelkerke $\mathrm{R}^{2}$} & .015 & .010 & .028 & .003 & .047 & .050 & .001 & .037 & .042 \\
\hline \multicolumn{2}{|c|}{-2 Log likelihood } & 490.55 & 493.64 & 481.60 & 975.583 & 985.93 & 948.627 & 989.859 & 977.815 & 966.563 \\
\hline \multicolumn{2}{|c|}{$\begin{array}{l}\% \quad \text { of correct } \\
\text { Prediction }\end{array}$} & 89.3 & 89.4 & 89.4 & 60.2 & 60.1 & 60.7 & 58.0 & 57.8 & 57.9 \\
\hline \multicolumn{2}{|c|}{$\mathrm{N}$ (\% of the sample) } & $729(97.3)$ & $734(98.0)$ & $728(97.2)$ & $727(97.1)$ & $732(97.7)$ & $726(96.9)$ & $728(97.2)$ & $733(97.9)$ & $727(97.1)$ \\
\hline
\end{tabular}

Exponentiated coefficients; $95 \%$ confidence intervals in brackets ${ }^{*} p<.05,{ }^{* *} p<.01,{ }^{* * *} p<.001$ 
(Table continued)

\begin{tabular}{|c|c|c|c|c|c|c|c|c|c|c|}
\hline \multirow{3}{*}{\multicolumn{2}{|c|}{$\begin{array}{l}\text { Independent } \\
\text { variable }\end{array}$}} & \multicolumn{9}{|c|}{$\begin{array}{l}\text { Dependent variables: School factors of anxiety } \\
\text { OR [CI 95\%] }\end{array}$} \\
\hline & & \multicolumn{3}{|c|}{ School/Class facilities } & \multicolumn{3}{|c|}{ School safety } & \multicolumn{3}{|c|}{ Factors related to subjects } \\
\hline & & Model A4 & Model B4 & Model C4 & Model A5 & Model B5 & Model C5 & Model A6 & Model B6 & Model C6 \\
\hline \multirow[t]{2}{*}{ Sex } & Male & $\begin{array}{l}1.131 \\
{[.833-1.537]}\end{array}$ & & $\begin{array}{l}1.197[.874- \\
1.640]\end{array}$ & $\begin{array}{l}.917[.685- \\
1.227]\end{array}$ & & $\begin{array}{l}.931[.691- \\
1.254]\end{array}$ & $\begin{array}{l}.975[.727- \\
1.308]\end{array}$ & & $\begin{array}{l}.976[.725- \\
1.313]\end{array}$ \\
\hline & Female & 1 & & 1 & 1 & & 1 & 1 & & 1 \\
\hline \multirow[t]{4}{*}{ Grade } & 6 & & $\begin{array}{l}3.137 * * * \\
{[1.937-} \\
5.083]\end{array}$ & $\begin{array}{l}3.307 * * * \\
{[2.031-} \\
5.385]\end{array}$ & & $\begin{array}{l}2.692 * * * \\
{[1.728-} \\
4.194]\end{array}$ & $\begin{array}{l}2.771 * * * \\
{[1.774-} \\
4.328]\end{array}$ & & $\begin{array}{l}.888 \\
{[.579-} \\
1.363]\end{array}$ & $\begin{array}{l}.888[.578- \\
1.364]\end{array}$ \\
\hline & 7 & & $\begin{array}{l}2.191 * * * \\
{[1.351-} \\
3.554] \\
\end{array}$ & $\begin{array}{l}2.351 * * * \\
{[1.440-} \\
3.837] \\
\end{array}$ & & $\begin{array}{l}1.855 * * \\
{[1.199-} \\
2.871] \\
\end{array}$ & $\begin{array}{l}1.914 * * \\
{[1.232-} \\
2.974] \\
\end{array}$ & & $\begin{array}{l}1.190 \\
{[.777-} \\
1.823] \\
\end{array}$ & $\begin{array}{l}1.205 \\
{[.784-} \\
1.853] \\
\end{array}$ \\
\hline & 8 & & $\begin{array}{l}1.838 * \\
{[1.134-} \\
2.981] \\
\end{array}$ & $\begin{array}{l}1.911 * * \\
{[1.173-} \\
3.114] \\
\end{array}$ & & $\begin{array}{l}1.921 * * \\
{[1.248-} \\
2.957]\end{array}$ & $\begin{array}{l}1.964 * * \\
{[1.272-} \\
3.032]\end{array}$ & & $\begin{array}{l}1.073 \\
{[.705-} \\
1.634] \\
\end{array}$ & $\begin{array}{l}1.113 \\
{[.730-} \\
1.697] \\
\end{array}$ \\
\hline & 9 & & 1 & 1 & & 1 & 1 & & 1 & 1 \\
\hline \multicolumn{2}{|c|}{ Constant } & $-.710 * * *$ & $-1.332 * * *$ & $-1.463 * * *$ & $-.068 * * *$ & $-.712 * * *$ & $-.693 * * *$ & $.293 * *$ & .240 & .242 \\
\hline \multicolumn{2}{|c|}{$\mathrm{p}$} & .430 & .000 & .000 & .559 & .000 & .000 & .862 & .560 & .659 \\
\hline \multicolumn{2}{|c|}{ Nagelkerke $\mathrm{R}^{2}$} & .001 & .044 & .049 & .001 & .036 & .039 & .000 & .004 & .004 \\
\hline \multicolumn{2}{|c|}{-2 Log likelihood } & 935.136 & 917.514 & 908.416 & 1005.182 & 991.868 & 982.338 & 993.731 & 999.003 & 990.209 \\
\hline \multicolumn{2}{|c|}{$\begin{array}{l}\% \text { of correct } \\
\text { prediction }\end{array}$} & 65.6 & 65.7 & 65.6 & 52.8 & 56.4 & 56.5 & 56.9 & 56.8 & 56.9 \\
\hline \multicolumn{2}{|c|}{$\mathrm{N}(\%$ of sample) } & $727(97.1)$ & $732(97.7)$ & 726 (96.9) & $727(97.1)$ & $732(97.7)$ & $726(96.9)$ & $727(97.1)$ & $732(97.7)$ & $726(96.9)$ \\
\hline
\end{tabular}

Exponentiated coefficients; $95 \%$ confidence intervals in brackets

${ }^{*} p<.05,{ }^{* *} p<.01,{ }^{* * *} p<.001$ 


\section{DISCUSSION}

\section{School factors of anxiety among adolescents}

Scores and exams were the factors that caused the most anxiety among adolescents. In Vietnam, it is evident that scores and exams cause pressure for most of the students. The ultimate purpose of students at school is to pass the exams with as higher marks as possible. For junior students, the essential exam is the graduate junior school exam, which will decide which high school they are in while that for high school students is the university entrance exam. In big cities like Hanoi and Ho Chi Minh, there is higher competition for a public school due to the limited number of high-quality public schools. Private schools are usually with high school fee that prevents many students from midle or lower income families. Therefore, parents typically put pressure on their children in studying and exams. A study of Dinh (2014) revealed that it was not the subjects at school, the stout curriculum, but the pressure from family created negative emotions for adolescents (including anxiety). Tran et al. (2014) và Nguyen (2018) revealed that studying was the core factor that created stress and anxiety among adolescents. In a study conducted by Do and Dinh (2020), scores played an essential meaning to students. The ranking was standard for students to compare themselves with other students. Therefore, low scores in academics meant shame to friends. Besides, students with low scores usually received word violence and physical punishment from parents and sometimes teachers (Do \& Dinh, 2020).

Students were always in a high pressure of study harder and harder. However, the more parents put pressure on their children, the higher risk that students had anxiety, which negatively impacted their academic performance. The negative correlation between anxiety and academic achievement was confirmed in previous studies (Liu et al., 2018; Owens et al., 2008; Yousefi et al., 2010). It is necessary to reduce the pressure in scores and exams for adolescents in Vietnam.

The association between gender, grade and school factors of anxiety among adolescents in secondary schools (binary regression)

\section{Scores and grades created more anxiety in females than in males}

In this study, factors related to scores and grades created anxiety higher among female students than their counterparts. Some previous studies shared the same finding (Shen et al., 2015). However, the reasons for this finding were not appropriately explained (Liu et al., 2018). Regarding physical development, females usually experienced puberty earlier than males (Marceau et al., 2011; Mendle et al., 2019) and were more sensitive than males. When compared to boys, adolescent girls' self-esteem tended to be more influenced by poor body image, selfconsciousness, and academic adjustment. These factors may put girls at higher risk than boys (Denmark et al., 2000).

Regarding the cultural aspect, Vietnam was under the influence of Confucianism, in which the role of females was limited in comparison to males. Hence, females were more likely to study harder to confirm their role in class and society. Data showed that females were more anxious than males in scores and exams. However, the data also showed that the correct prediction rates of all regression models and the relative amplitude of gender impact on this factor were quite small. Understandably, there were many other school factors that might caused the anxiety among adolescents. 
Factors related to the association with friends, communication with teachers, school/class facilities and school safety created higher anxiety among students in grade 6,7 and 8 than those in grade 9.

The handling of problems in relationships with friends, communication with teachers and school/classroom facilities, and school safety among adolescents depended heavily on emotional-social capacity. Students at lower grades were more limited in psychological, social, and emotional abilities (Tran et al., 2019). This might explain why students at lower grades were more anxious in relationships with friends, communication with teachers, school/classroom facilities, and school safety. However, the correct forecasting rate of all regression models and the relative amplitude of the grade on the anxiety factors were quite small. Perhaps, individual psychological factors or familial factors might have a more substantial impact on adolescents than school factors that caused anxiety for adolescents.

\section{Limitations}

The study has several limitations. First, the primary evidence defects arise from the sampling process used. The random selection of participants alleviates this concern significantly but does not entirely remedy that shortcoming. Second, this is a cross-sectional study that cannot explain the causes and results associated with all school-related factors. Third, psychological and social factors specific to each gender and class were not included in this study. Fourth, participants were students in the two biggest cities in Vietnam. Therefore, it can not represent the adolescent samples in different geographical locations in Vietnam. Future studies should address these limitations.
The current research explored the anxiety of secondary school students in four secondary schools in Ha Noi Capital City and Ho Chi Minh City, Vietnam. It is amongst the first studies investigating the school factors causing anxiety for secondary school students related to their academic achievements in Ha Noi City and Ho Chi Minh City, Vietnam, to the best of authors' knowledge. According to the research results, scores and exams were the most important factors that cause anxiety among adolescents in Vietnam. Females were more likely to be anxious in scores and exams than males. Relationship with friends, communication with teachers, school/class facilities, and school safety caused more anxiety among students in lower grades. The results of this research are necessary for Vietnamese educational leaders and teachers to provide prevention and intervention programs to reduce anxiety among adolescents in Vietnamese secondary schools. Further research is recommended to identify the underlying reasons for no gender differences in self-control ability among secondary school students in Northern and Southern Vietnam. It is also suggested that research will be conducted involving students from more different areas in Vietnam so that the research results can be generalized.

\section{Acknowledgments}

We would like to thank all adolescents in four secondary schools in Ha Noi Capital City and Ho Chi Minh City, who agreed to participate in this study. We express our thanks to the support of school directors, teachers, and colleagues in collecting data process. We would also like to thank the Vietnam Academy of Social Sciences, Hanoi, Vietnam, for providing funds to this study.

\section{CONCLUSION}


Scope of work of authors

D. T. H.V - Study design

D.T.H.V., D.T.L.H., \& P.T.M.H - Data

collection

D.T.H.V., D.T.L.H., \& P.T.M.H - Statistical

\section{REFERENCES}

[1] Cobham, V. E., Hickling, A., Kimball, H., Thomas, H. J., Scott, J. G., \& Middeldorp, C. M. (2019). Systematic Review: Anxiety in Children and Adolescents With Chronic Medical Conditions. Journal of the American Academy of Child \& Adolescent Psychiatry.

[2] Corp. I. (2012). SPSS Statistics for Windows, version 22.0. IBM Corp.

[3] Costello, E. J., Mustillo, S., Erkanli, A., Keeler, G., \& Angold A. (2003). Prevalence and development of psychiatric disorders in childhood and adolescence. Arch Gen Psychiatry, 60(3), 837-844.

[4] Denmark, F., Rabinowitz, V., Sechzer, J. (2000). Engendering Psychology: Bringing Women into Focus. Allyn \& Bacon.

[5] Dillman, D. A. (2000). Mail and Internet surveys: The tailored design method. John Wiley \& Sons.

[6] Dinh, T. H. V. (2014). Negative emotions in the social relationship among adolescents. Journal of Psychology, 5, 53-66. (Vietnamese)

[7] Do, T. L. H., \& Dinh, T. H. V. (2020). School factors created anxiety among junior high school students: the relationship with gender and grade. Journal of Psychology, 6(255), 31-42.

[8] Deb, S., Chatterjee, P., \& Walsh, K. (2010). Anxiety among high school students in India: Comparisons across gender, school type, social strata, and perceptions of quality time with parents. Australian analysis

D.T.H.V., D.T.L.H - Data interpretation

D.T.H.V., D.T.L.H - Manuscript preparation

D.T.L.H - Literature search

P.T.M.H - Funds collection

Journal of Educational \& Developmental Psychology, 10(7), 18-31

[9] Essau, C. A., Leung, P. W. L., Conradt, J., Cheng, H., \& Wong, T. (2008). Anxiety symptoms in Chinese and german adolescents: their relationship with early learning experiences, perfectionism, and learning motivation. Depression and anxiety, 25(6), 801-810

[10] Grant, D.M. (2013). Anxiety in Adolescence. In O'Donohue, W., Benuto, L., \& Tolle, L. W. (Eds.), Handbook of Adolescent Health Psychology (pp. 507-519). Springer.

[11] Jin, Y., He, L., Kang, Y., Chen, Y., Lu, W., Ren, X., Song, X., Wang, L., Nie, Z., Guo, D. (2014). Prevalence and Risk Factors of Anxiety Status among Students Aged 13-26 Years. Int. J. Clin. Exp. Med, 7(3), 4420-4432.

[12] Langelier, C. A. (2011). Mood Management: A Cognitive Behavioral Skills Building Program for Adolescents. SAGE Publications, Inc.

[13] Liu, H., Shi, Y., Auden, E., \& Rozelle, S. (2018). Anxiety in Rural Chinese Children and Adolescents: Comparisons across Provinces and among Subgroups. Int. J. Environ. Res. Public Health, 15, 2087.

[14] Marceau, K., Ram, N., Houts, R. M., Grimm, K, J., \& Susman, E. J. (2011). Individual Differences in Boys' and Girls' Timing and Tempo of Puberty: Modeling Development With Nonlinear Growth Models. Dev Psychol, 47(5), 1389-1409. 
[15] Mardomingo, M. J. (2005). Trastornos de ansiedad en el adolescente. [Anxiety disorders in the adolescent.] Pediatr Integral, 9(2), 125-134.

[16] Mendle, J., Beltz, A. M., \& Carter, R. (2019). Understanding Puberty and Its Measurement: Ideas for Research in a New Generation. Journal of research on adolescence, 29(1), 82-95

[17] Nguyen, T. V. (2018). The status of anxiety disorders among high school students in Ho Chi Minh city-based on STAI. Journal of Education, 425(6), 19-22. (Vietnamese)

[18] Nguyen, T. T., Dedding, C., Pham, T. T., Wright, P., \& Bunders. J. (2013). Depression, anxiety, and suicidal ideation among Vietnamese secondary school students and proposed solutions: a cross-sectional study. BMC Public Health, 13(5), 1195-1207.

[19] Nguyen, D. T,. Wright, E. P., Dedding, C., Pham, T. T., \& Bunders, J. (2019). Low Self-Esteem and Its Association With Anxiety, Depression, and Suicidal Ideation in Vietnamese Secondary School Students: A Cross-Sectional Study. Front Psychiatry, 10, 689-695.

[20] Owens, M., Stevenson, J., Norgate, R., \& Hadwin, J. A. (2008). Processing Efficiency Theory in Children: Working Memory as a Mediator between Trait Anxiety and Academic Performance. Anxiety Stress Coping, 21(3), 417-430.

[21] Pine, D. S., Wasserman, G. A. \& Workman, S. B. (1999). Memory and anxiety in prepubertal boys at risk for delinquency. Journal of the American Academy of Child Adolescent Psychiatry, 38, 10241031.

[22] Seligman, M. E., Walker, E. F., \& Rosenhan, D. L. (2001). Abnormal Psychology. Norton Publisher.
[23] Shen, M., Gao, J., Liang, Z., Wang, Y., Du, Y., \&Stallones, L. (2015). Parental Migration Patterns and Risk of Depression and Anxiety Disorder among Rural Children Aged 10-18 Years in China: A Cross-Sectional Study. BMJ Open 2015, 5(6), 78-92.

[24] Silk, J. S., Steinberg, L., \& Morris, A. S. (2003). Adolescents' emotion regulation in daily life: links to depressive symptoms and problem behavior. Child development, 74(6), 1869-80.

[25] Spielberger, C. D., Gorsuch, R. L., \& Lushene, R. E. (1970). Manual for the State-Trait Anxiety Inventory. Consulting Psychologists Press.

[26] Tran, T. T. A, Dinh, T. H. V, Nguyen, P. C. T., \& Dau, M. L. (2019). The current status of social-emotional capacity among adolescents. Vietnam Journal of Educational Science, 19, 110-114. (Vietnamese)

[27] Xing, Y. (2008). The Stdy on the Difference of Anxiety across Rural Chinese Children. J. Nanchang Coll., 1(4), 119-121.

[28] Yousefi, F., Talib, M. A., Mansor, M. B., Juhari, R. B., \& Redzuan, M. (2010). The Relationship between Test-Anxiety and Academic Achievement among Iranian Adolescents. Asian Soc. Sci., 6(3), 100115. 